\title{
STUDIES ON ALCOHOL DIURESIS. III. THE RESPONSE TO ETHYL ALCOHOL IN CERTAIN DISEASE STATES CHAR- ACTERIZED BY IMPAIRED WATER TOLERANCE ${ }^{1}$
}

\author{
By EZRA LAMDIN,² CHARLES R. KLEEMAN, MILTON RUBINI, AND \\ FRANKLIN H. EPSTEIN \\ (From the Department of Medicine, Yale University School of Medicine, New Haven, Conn.)
}

(Submitted for publication November 14, 1955; accepted January 4, 1956)

Ethyl alcohol, when imbibed by normal subjects, stimulates a diuresis of water and blocks the antidiuretic effects of such stimuli as the passive erect posture, infusions of hypertonic saline, venous congestion of the lower limbs, and acetylcholine. It has been shown to inhibit transiently the release of the antidiuretic hormone $(\mathrm{ADH})$ from the posterior pituitary gland, regardless of the nature of the provoking antidiuretic stimulus (1-6). Recently, Dicker (7) has demonstrated an almost complete absence of antidiuretic activity in the blood of rats given lethal amounts of ethyl alcohol. These data afford convincing argument localizing the site of action of this compound to the supraoptico-hypophyseal system.

An excessive activity of $\mathrm{ADH}$ has been invoked by many investigators in an attempt to explain the impaired excretion of water which is a feature of certain disease states. In view of its known action in inhibiting the release of this hormone, it was of interest to observe the effect of alcohol when administered to patients with diseases characterized by faulty metabolism of water.

\section{MATERIALS AND METHODS}

Observations were made upon 16 hospitalized patients with the following diagnoses: cirrhosis (six), arteriosclerotic, hypertensive, or valvular heart disease with congestive failure (four), cor pulmonale (one), superior vena-caval syndrome (one), nephrotic syndrome (one), Addison's disease (two), and hypoadrenocorticism secondary to panhypopituitarism (one). All but the last three had clinically evident fluid retention (edema, ascites, or both). One Addisonian (R. M.) was receiving cortisone at the time of the study, while the other, and the patient with panhypopituitarism, were

\footnotetext{
1 Supported in part by the United States Public Health Service, Grant H-834.

2 Work done during tenure as U.S.P.H.S. Postdoctoral fellow. Present address: Veterans Administration Hospital, Boston, Massachusetts.
}

not. Impaired water tolerance is defined as failure to excrete, within three to four hours, at least fifty per cent of 1000 to 1500 milliliters of water, administered either orally or intravenously as iso- or hypotonic fructose or glucose, prior to the day of testing.

Ten patients each received a single dose of alcohol ( 35 to 60 grams) as either 95 per cent laboratory alcohol or 100 proof Bourbon whiskey, made up to a total volume of approximately 150 to $180 \mathrm{cc}$. with fruit juice and ice. The remaining six patients each received two to four doses of 25 to 45 grams each (total 70 to 140 grams) at intervals of one or two hours.

In an additional study, a single 45-gram dose of alcohol was ingested by two adequately hydrated patients with diabetes insipidus, who were not receiving posterior pituitary therapy at the time.

From 7:00 to 7:30 a.m. on the day of the test, the patient ate a light breakfast including 400 to $600 \mathrm{cc}$. of fluid. About one hour later, the patient emptied his bladder, and assumed the recumbent or semi-recumbent position, standing only to void. Alcohol was generally given two to three hours afterwards. Water loads of 1000 to $1500 \mathrm{cc}$. (either by mouth in 15 to 20 minutes, or as 2.5 per cent or 5 per cent glucose or fructose in one hour intravenously) were administered to five patients one and $a$ half to three and $a$ half hours before, and to two patients concurrently with, the ethanol. The other patients drank smaller amounts of water, as indicated in the tables. Each study lasted approximately five to seven hours.

Blood was drawn at approximately hourly intervals for the determination of sodium, creatinine and osmolarity (freezing-point depression) in the serum, and half-hourly for the determination of the concentration of alcohol. Urine, for the determination of sodium, creatinine and osmolarity, was collected in one-half- to two-hourly periods, by spontaneous voiding or indwelling catheter.

The chemical methods and calculations employed have been described in a previous publication (1).

$$
\begin{aligned}
& \quad \mathrm{C}_{\mathrm{oem}}=\text { osmolar clearance }=\frac{\mathrm{U}_{\text {oem }} \mathrm{V}}{\mathrm{P}_{\text {oem }}} \\
& \mathrm{C}_{\mathrm{H}_{2} \mathrm{O}}=\mathrm{V}-\mathrm{C}_{\mathrm{oem}}
\end{aligned}
$$




\section{RESULTS}

For purposes of this study, a diuretic response is defined as the excretion of fifty per cent or more of an administered load of water within four hours after the ingestion of alcohol. For those patients who were not subjected to a provocative water load, a positive response consisted of an increase in urine flow to values significantly greater than those of the control period, a fall in urinary osmolarity and a rise in free water clearance $\left(\mathrm{C}_{\mathrm{H}_{2} \mathrm{O}}\right)$.

I. Patients with diabetes insipidus, Addison's disease, and panhypopituitarism (Tables I and IIa)

Alcohol did not further augment the relatively high rates of urinary flow in two patients with diabetes insipidus (Table I).

In one patient with Addison's disease and one patient with hypopituitarism (patients 1 and 2, Table IIa), neither of whom was receiving cortisone, alcohol did not provoke a water diuresis. Patient 3, R. M., an Addisonian treated with cortisone, who had regained the normal diuretic response to water, showed a similar normal diuretic response following alcohol.

\section{Patients with clinically evident retention of fluid (Table IIb)}

In only four of thirteen patients in this category (patients 4 to 7) was ethanol successful in provoking diuresis. One of these, P. M., also responded normally to ingestion of water, during the control period, as evidenced by urine flows of 4.0 and $3.5 \mathrm{cc}$. per min in periods 2 and 3, respectively, following a water load given one hour before the beginning of period 2. Imbibing alcohol when the rate of urine flow was falling resulted in a second diuresis. Patient J. L., in whom impaired tolerance to water loading is suggested by flows of $0.4 \mathrm{cc}$. per min. during periods 1 and 2 (i.e., during the second hour following ingestion of $500 \mathrm{cc}$. of water), was, however, able to diurese normally upon water loading two weeks later, following paracentesis and salt restriction. The response of patient $6, \mathrm{D} . \mathrm{McC}$., is anomalous. From the temporal relationship between the ingestion of water, ingestion of alcohol, and onset of diuresis, the diuresis seems to be more in response to water than to alcohol. However, on two previ-
TABLE I

Response to ethyl alcohol of two patients with diabetes insipidus

\begin{tabular}{ccc}
\hline \hline $\begin{array}{c}\text { Period } \\
\text { No. }\end{array}$ & $\begin{array}{c}\text { Elapsed } \\
\text { time } \\
\text { min. }\end{array}$ & $\begin{array}{c}\text { Urinary } \\
\text { flow } \\
\text { cc. } / \text { min. }\end{array}$ \\
\hline \multicolumn{3}{c}{ Patient I-J. V. } \\
1 & 70 & \\
2 & 110 & 8.0 \\
3 & 158 & 11.2 \\
$4^{*}$ & 213 & 10.8 \\
5 & 332 & 11.0 \\
& Patient II-S. C. & 5.6 \\
1 & 30 & \\
2 & 60 & 6.2 \\
3 & 110 & 7.7 \\
4 & 135 & 6.7 \\
$5^{*}$ & 198 & 10.0 \\
6 & 240 & 4.21 \\
7 & 270 & 8.8 \\
& & 8.3 \\
\hline
\end{tabular}

*Alcohol was administered at the beginning of this period.

ous occasions, unequivocal impairment in excretion of a water load had been demonstrated. The least dramatic effect of ethanol is seen in patient A. D., who excreted only 53 per cent of the administered load of water. However, following each of two doses of alcohol, an increased rate of urine flow ensued, unassociated with any change in the clearance of endogenous creatinine.

The remaining nine patients did not have a diuretic response to alcohol, regardless of whether one dose (patients 8 to 13) or several doses (patients 14 to 16 ) were administered.

In comparing those who responded with a diuresis to alcohol with those who did not, no striking differences were apparent with respect to concentration in the serum and urine of sodium or total solutes, their rates of excretion, or the clearance of endogenous creatinine. Comparable levels of alcohol in the blood were attained in the two groups, and are consistent with values observed in normal subjects receiving equivalent amounts of ethanol $(1,2)$. Of those responding who received more than one dose of alcohol (patients 5 to 7 ), some diuretic effect was obtained from the first dose, whereas up to four doses in unresponsive patients failed to provoke an increase in the flow of urine. Patients with impaired water tolerance secondary to cirrhosis and to congestive heart failure were represented in both groups; thus the nature of the underlying disease did not, per se, appear to determine the response of any given patient to the diuretic stimulus of alcohol. 


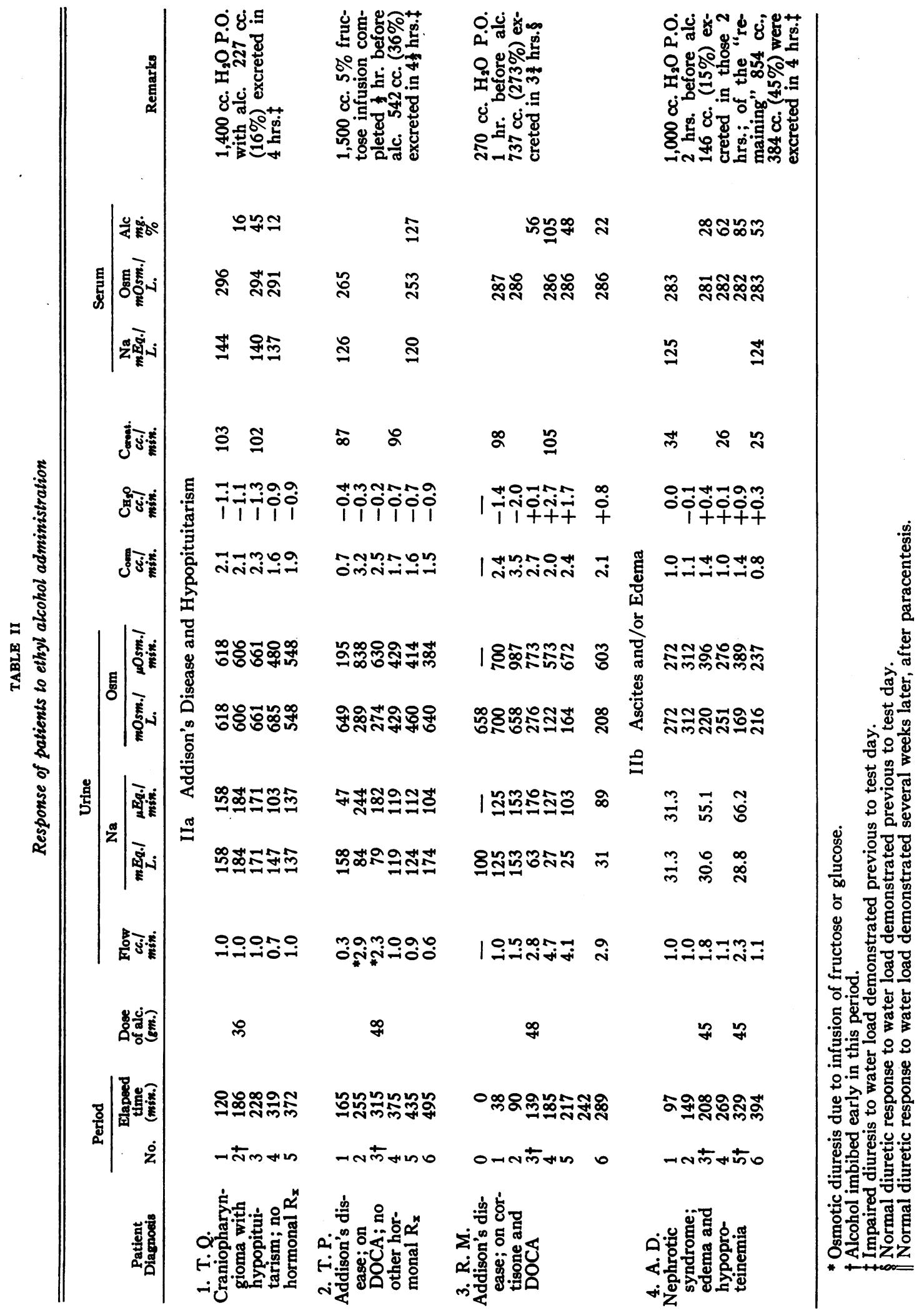




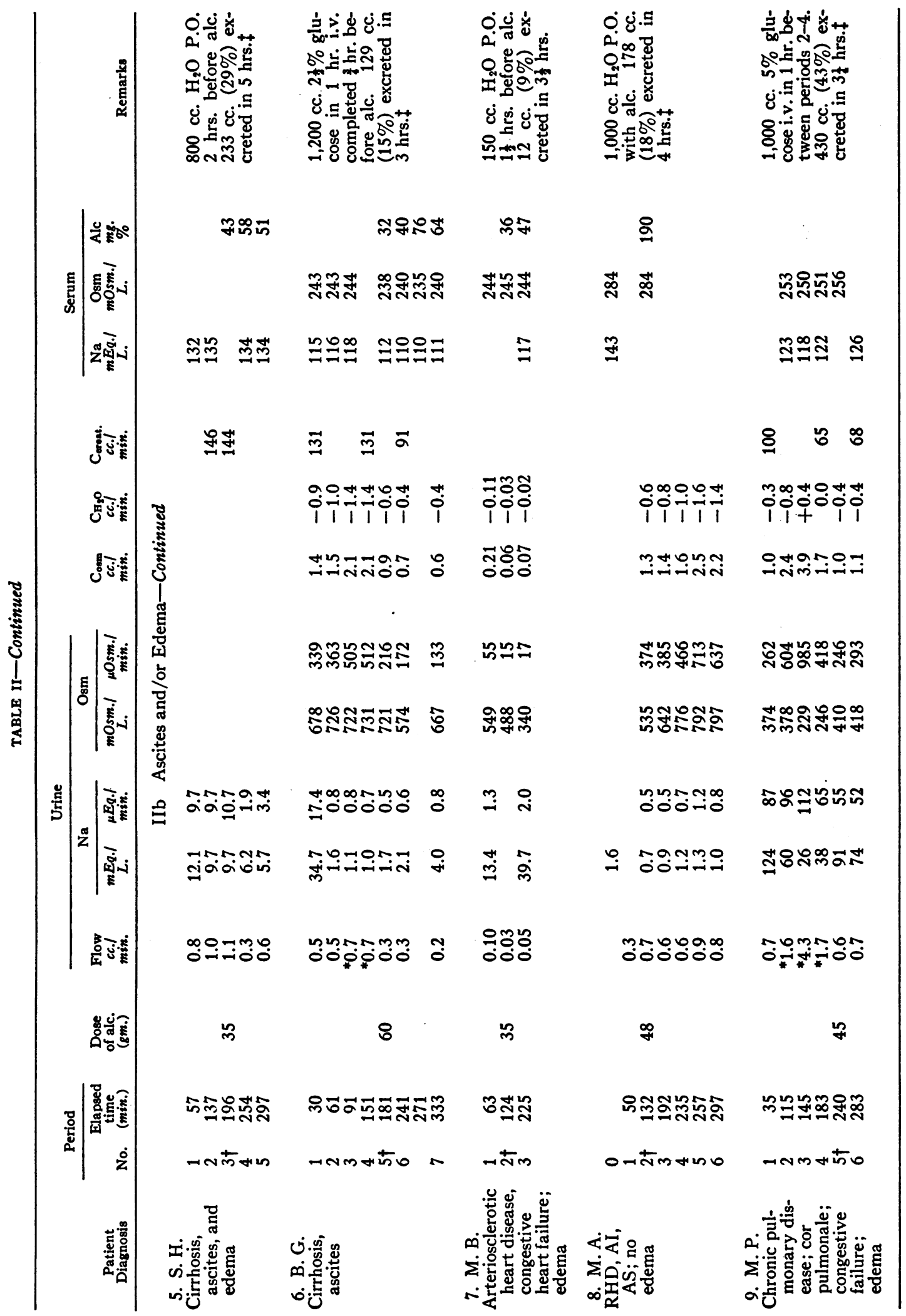




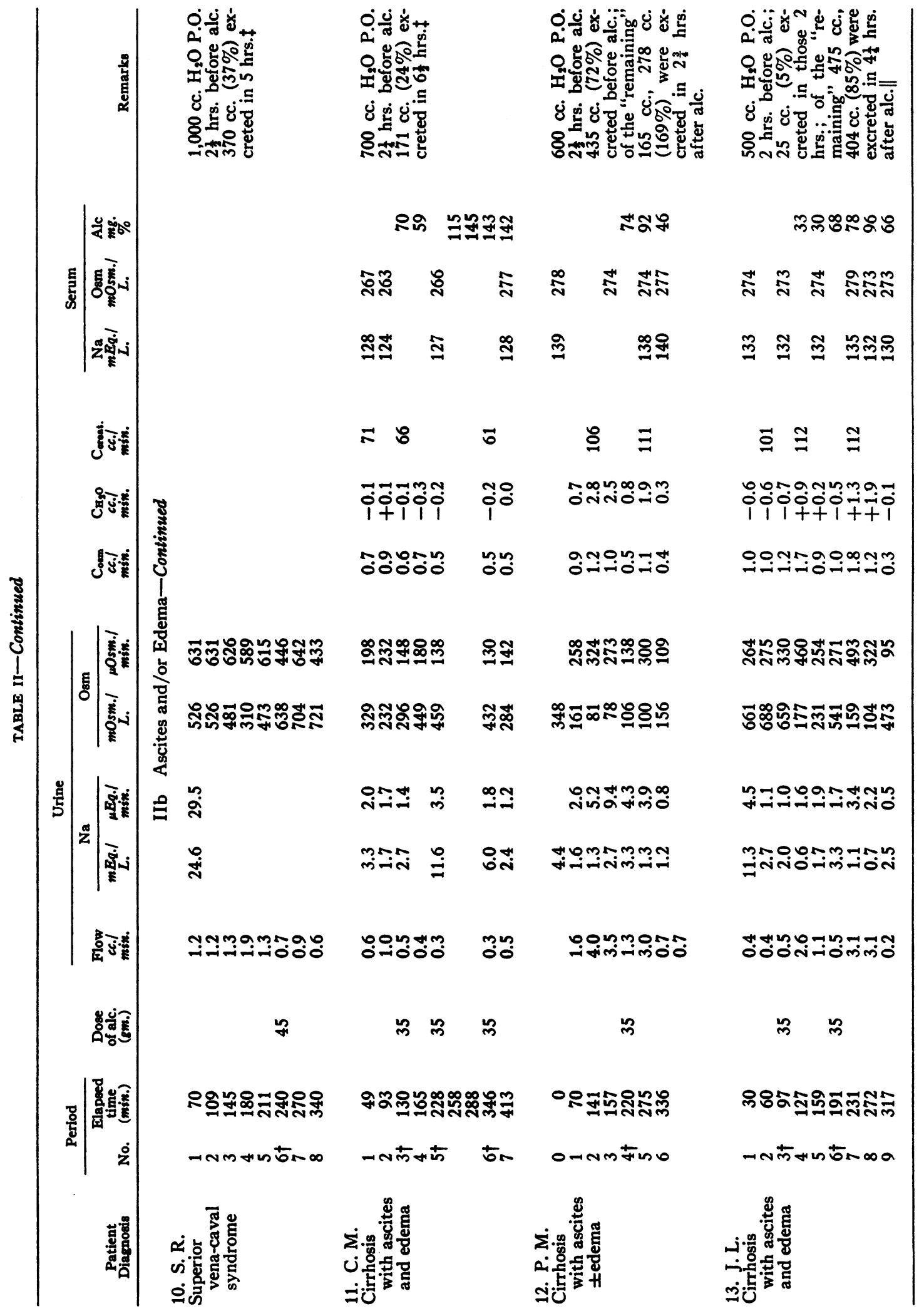


RESPONSE TO ALCOHOL IN WATER-RETAINING DISORDERS

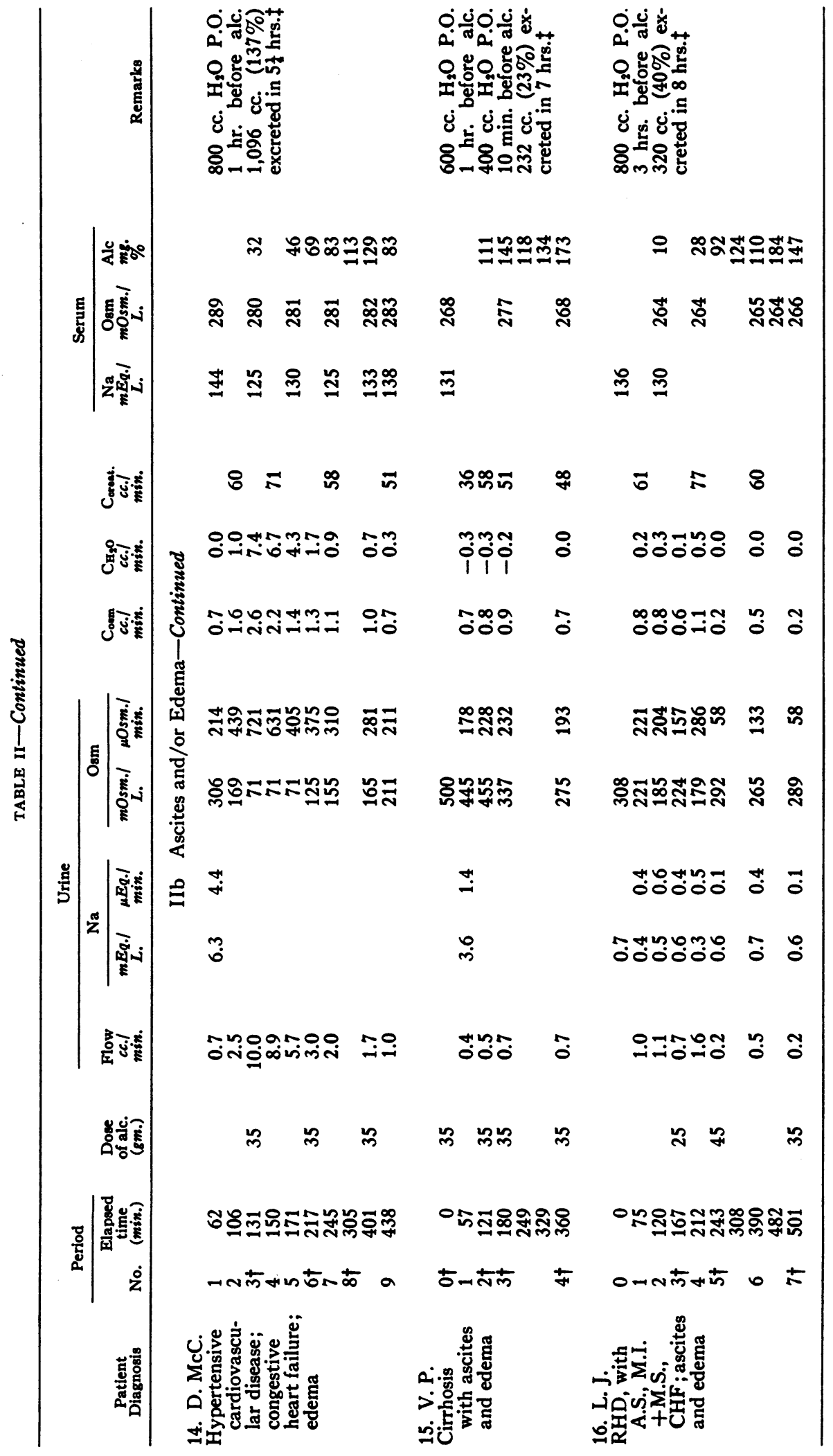




\section{DISCUSSION}

That ethanol caused no further increase in the urine flow of patients with diabetes insipidus is not surprising. If the action of alcohol is indeed inhibition of the release of $\mathrm{ADH}$, then when the release of this hormone is already minimal or absent, owing to damage to the neurohypophysis, further suppression could not reasonably occur. This observation merely helps affirm earlier argument localizing the site and mechanism of alcohol diuresis.

Because of the known action of the antidiuretic hormone in inhibiting the excretion of water, attempts have been made to relate the impaired water metabolism of various clinical conditions, with and without edema, to over-production of $\mathrm{ADH}$ (8), diminished destruction of $\mathrm{ADH}$, or increased sensitivity to this hormone (9). In support of these hypotheses are the reported findings of an elevated amount of antidiuretic substances in the urine or blood of patients with such conditions. Elevated values have been reported in cirrhosis (10-12), congestive heart failure $(13,14)$, hypertension (15), and Addison's disease (11). However, these substances are not the same in all instances, nor have they been shown conclusively to be identical with ADH (13), Perry and Fyles (16) found no correlation between levels of an antidiuretic substance and edema or liver damage, and no significant difference in antidiuretic activity between the sera of normals and patients with congestive failure or cirrhosis. Nelson and Welt (17) concluded that the patient with cirrhosis and ascites showed no evidence of an increased sensitivity to, or an inability to eliminate or inactivate, endogenous or exogenous posterior pituitary hormone. van Dyke, Ames, and Plough (18), and Stein, Schwartz, and Mirsky (19) report that despite increased levels of antidiuretic substance in some patients, no correlation between this and impaired water metabolism could be detected. van Dyke (20) has justly criticized much of the methodology which has been employed in the assay of antidiuretic substances.

Gaunt (21), working with animals, and Lloyd and Lobotsky $(9,11)$ on the basis of human studies, have postulated an antagonistic relationship between the adrenal cortex and the posterior pituitary with respect to the control of the balance of water in the body. Thus, in the adrenalectomized rat or the adrenal-insufficient human, an increased amount of ADH may accumulate in the blood, preventing excretion of a water load in normal fashion. The administration of corticosteroids, according to this theory, by antagonizing the action of ADH (or of some factor which promotes the release of $\mathrm{ADH}$ ), permits normal water diuresis to ensue. However, if the action of the corticosteroids is in fact the inhibition of $\mathrm{ADH}$, one should expect similar results from alcohol. In the present studies, a patient with Addison's disease (T. P.) and a patient with panhypopituitarism (T. Q.), neither of whom was receiving corticoid therapy, both failed to have a diuresis after ingesting alcohol. The administration of cortisone, however, which is essential for the correction of the abnormal water tolerance in these states, to another Addisonian (R. M.) also restored the responsiveness to alcohol. One may conclude, therefore, that the action of cortisone is probably not antagonistic to $\mathrm{ADH}$, but is rather "permissive" (22), allowing the organism, by mechanisms as yet undefined, to respond in normal fashion to the stimuli of both water and alcohol.

The inhibitory effect of alcohol on the neurohypophysis is transient. It appears to be related to the duration of the rise in the level of alcohol in the blood, rather than to the absolute level attained (4). Therefore, the administration of repeated doses of ethanol, when the blood level is falling, should theoretically prolong the inhibition established by the initial dose, and allow for a more leisurely dissipation of circulating $\mathrm{ADH}$. A response to a second dose, in the face of minimal or absent response to the first, would suggest either that the destruction of $\mathrm{ADH}$ is impaired, or that an increased amount of this hormone was being secreted by the posterior pituitary into the blood. However, in patients who were unresponsive, up to four doses of alcohol failed to provoke diuresis, whereas in those who did respond to multiple doses, some increase in urine flow followed the ingestion of the initial dose.

Of the sixteen patients observed in the present study, all but three (R. M., P. M., and J. L.) had unequivocally impaired responses to water. Since ethyl alcohol, a substance known to inhibit the release of $\mathrm{ADH}$ from the neurohypophysis, failed to provoke diuresis in 11 of 13 patients with abnormal water tolerance, the present data do not 
support the hypothesis that excessive activity of the antidiuretic hormone of the posterior pituitary is the most important causative factor in the impaired water metabolism of the diseases studied. Although some activity of $\mathrm{ADH}$ cannot be excluded, other factors, the nature of which remain unknown, may well play the dominant role in the pathogenesis of the impaired water tolerance that characterizes these states. Whatever these waterretaining stimuli might be, it is probable that the intensity of their action varies from individual to individual, regardless of the nature of the disease. Should this be true, the extent of water diuresis in the absence of $\mathrm{ADH}$ (or in response to alcohol) would be determined by the intensity of action of these extra-neurohypophyseal factors.

\section{SUMMARY}

1. Ethyl alcohol, a known inhibitor of the release of $\mathrm{ADH}$ from the neurohypophysis, was administered orally to 16 patients with various diseases characterized by impaired water tolerance.

2. Eleven of thirteen patients in whom impaired water tolerance was demonstrated failed to respond to ethanol with a diuresis of water.

3. Cortisone restored the ability of one patient with Addison's disease to respond normally with a diuresis both to water and to alcohol.

4. These data do not support the contention that excessive activity of $\mathrm{ADH}$ is chiefly responsible for the disturbed water tolerance characterizing the disease states studied.

\section{REFERENCES}

1. Rubini, M. E., Kleeman, C. R., and Lamdin, E., Studies on alcohol diuresis. I. The effect of ethyl alcohol ingestion on water, electrolyte and acidbase metabolism. J. Clin. Invest., 1955, 34, 439.

2. Kleeman, C. R., Rubini, M. E., Lamdin, E., and Epstein, F. H., Studies on alcohol diuresis. II. The evaluation of ethyl alcohol as an inhibitor of the neurohypophysis. J. Clin. Invest., 1955, 34, 448.

3. Strauss, M. B., Rosenbaum, J. D., and Nelson, W. P., III, The effect of alcohol on the renal excretion of water and electrolyte. J. Clin. Invest., 1950, 29, 1053.

4. Eggleton, M. G., The diuretic action of alcohol in man. J. Physiol., 1942, 101, 172.

5. van Dyke, H. B., and Ames, R. G., Alcohol diuresis. Acta Endocrinol., 1951, 7, 110.

6. Pearce, M. L., and Newman, E. V., Some postural adjustments of salt and water excretion. J. Clin. Invest., 1954, 33, 1089.
7. Dicker, S. E., A method for the assay of very small amounts of antidiuretic activity with a note on the antidiuretic titre of rats' blood. J. Physiol., 1953, $122,149$.

8. White, A. G., Rubin, G., and Leiter, L., Studies in edema. III. The effect of Pitressin on the renal excretion of water and electrolytes in patients with and without liver disease. J. Clin. Invest., 1951, 30, 1287.

9. Lloyd, C. W., Some clinical aspects of adrenal cortical and fluid metabolism in Recent Progress in Hormone Research, G. Pincus, Ed., New York, Academic Press, 1952, vol. 7, p. 469.

10. Ralli, E. P., Robson, J. S., Clarke, D., and Hoagland, C. L., Factors influencing ascites in patients with cirrhosis of the liver. J. Clin. Invest., 1945, 24, 316.

11. Lloyd, C. W., and Lobotsky, J., Serum antidiuretic substances and urinary corticosteroid in the human. J. Clin. Endocrinol., 1950, 10, 318.

12. Sims, J. L., A comparison of renal function with urinary antidiuretic activity in cirrhosis of the liver with ascites. J. Lab. \& Clin. Mod., 1950, 36, 990.

13. Bercu, B. A., Rokaw, S. N., and Massie, E., Antidiuretic action of the urine of patients in cardiac failure. Circulation, 1950, 2, 409.

14. Dochios, M., and Dreifus, L. S., Antidiuretic hormone studies in patients presenting edema. Am. J. Med. Sc., 1951, 222, 538.

15. Ellis, M. E., and Grollman, A., The antidiuretic hormone in the urine in experimental and clinical hypertension. Endocrinology, 1949, 44, 415.

16. Perry, W. F., and Fyles, T. W., Antidiuretic activity of the serum of normal and diseased subjects. $\mathrm{J}$. Clin. Endocrinol., 1953, 13, 64.

17. Nelson, W. P., III, and Welt, L. G., The effects of Pitressin on the metabolism and excretion of water and electrolytes in normal subjects and patients with cirrhosis and ascites. J. Clin. Invest., 1952, 31, 392.

18. van Dyke, H. B., Ames, R. G., and Plough, I. C., The excretion of antidiuretic hormone in the urine of patients with cirrhosis of the liver. Tr. A. Am. Physicians, 1950, 63, 35.

19. Stein, M., Schwartz, R., and Mirsky, I. A., The antidiuretic activity of plasma of patients with hepatic cirrhosis, congestive heart failure, hypertension and other clinical disorders. J. Clin. Invest., 1954, 33, 77.

20. van Dyke, H. B., The regulation of water excretion by the neurohypophysis. Bull. New York Acad. Med., 1953, 29, 24.

21. Gaunt, R., The adrenal cortex in salt and water metabolism in Recent Progress in Hormone Research, Pincus, G., Ed., New York, Academic Press, 1951, vol. 6, p. 247.

22. Ingle, D. J., Parameters of metabolic problems in Recent Progress in Hormone Research, Pincus, G., Ed., New York, Academic Press, 1951, vol. 6, p. 159. 